\title{
Orthopedics and Rheumatology
}

Open Access Journal

Research Article

Volume 2 Issue 3 - May 2016
Ortho \& Rheum Open Access J

Copyright (c) All rights are reserved by Florian Hess

\section{Lumbopelvic Stabilisation in Patients Over 50 with Posterior Pelvic Ring Fracture}

\author{
*Florian Hess, Ussamah Abu-Tair, Christoph Knoth and Ralph Zettl \\ Department of Orthopaedic Surgery and Traumatology, Kantonsspital Frauenfeld, Switzerland
}

Submission: April 28, 2016; Published: May 10, 2016

*Corresponding author: Florian Hess, Department of Orthopeadic Surgery and Traumatology, Kantonsspital Frauenfeld, Pfaffenholzstrasse 48501 Frauenfeld, Switzerland, Tel: 00415272377 11; Fax: 004152723 74 28; Email: florian.hess@stgag.ch

\begin{abstract}
Purpose: Pelvic fractures with posterior ring instability in people aged 50 and older are most often treated with ilio-sacral screw fixation or open plating techniques. The aim of the study was to assess the effectiveness of a less invasive technique, angular stable instrumentation.

Methods: Using a retrospective study design, we identified patients aged 50 and older who underwent angular stable instrumentation to treat a pelvic fracture from low energy trauma between November 2013 and November 2014. Of these 22 patients, eight were treated conservatively. Data on patient characteristics, complications and outcomes (radiological imaging and assessments of pain/daily activities) were extracted from medical records of 14 patients (mean age 72 years, $S D \pm 11.6$, range 53-91).

Results: Complete consolidation of the fracture was achieved in 12 patients and high levels of satisfaction were reported. There was a statistically significant improvement between the 6 week and 6 months scores (IADL $p=0.03$, Barthel Index $p=0.01$ ). None of the patients had wound healing problems or infections. Two patients died due to reasons unrelated to the operation. The mean duration of the operation was 49 minutes for unilateral procedures ( $S D \pm 8.3$, range 40-60) and 72 minutes $(S D \pm 16.9$, range 40-90) for bilateral procedures.

Conclusion:The clinical outcomes indicate that the lumbopelvic stabilisation is an effective technique for treating traumatic posterior pelvic ring fractures, even in older patients with poorer bone quality. The operation time is relatively short, mobilisation is early, the complication rate is low and patient satisfaction is high.
\end{abstract}

Keywords: Posterior pelvic ring fracture; Fragility fracture; Low energy trauma; Less invasive; Lumbopelvine stabilisation

\section{Introduction}

Changes in demographics and an increasing life expectancy worldwide [1] have contributed to a higher incidence of pelvic ring fractures in older adults [2-6]. Standard surgical techniques such as ilio sacral screw fixation have limitations, particularly with osteoporotic patients, and are associated with a high complication rate. The use of external fixators is not advisable in this population group [7-9]. Problems associated with prolonged immobilisation of up to six months include increase drisk of deep vein thrombosis and pulmonary embolus, loss of muscle mass, and decreased bone mineral density [10]. In addition, the pain associated with these fractures while walking or sitting often makes long-term use of pain medication unavoidable.

The lumbopelvic stabilisation technique has been used after sacrectomy [11], high-grade spondylolisthesis [12] and posterior pelvic ring fractures due to high-energy trauma $[13,14]$. This technique, when used in cases of posterior pelvic ring fractures, is done primarily in younger patients with high bone quality $[14,15]$. We believe this less invasive technique could also be advantageous when treating older and/or osteoporotic patients with traumatic posterior pelvic ring or insufficiency fractures because operation time is short and patients may be mobilized immediately after stabilisation without restrictions. The aim of this retrospective study was to investigate the effectiveness of this surgical technique in patients over 50 years by assessing clinical and radiological outcomes. We describe the procedure, including peri-operative conditions and complications experienced up to 6 months postoperatively.

\section{Materials and Methods}

\section{Patient population}

A total of 22 patients over 50 years old with Type B pelvic ring fractures (AO classification) were treated at our institution 
between November 2013 and October 2014. Due to low levels of pain and sufficient mobility, eight patients were treated conservatively. The remaining 14 patients were treated surgically with either unilateralor bilaterallumbopelvic stabilisation. Inclusion criteria for this study were patients over the age of 50 with posteriorly non-displaced type B fractures with previously unsuccessful conservative therapy.

Conservative therapy was determined 'unsuccessful' if physiotherapists were not able to mobilise the patient within three days following the trauma or if the patient was not able to walk on a walking frame within eight days. Type $\mathrm{C}$ lesions are primarily treated surgically due to the unstable fracture pattern and were excluded of the study. Furthermore, patients with pelvic fractures with relevant bleeding or hemodynamic unstable patients were also excluded. Data on demographics, fracture type surgical procedure, delay to surgery, operation time and length of hospitalisation were extracted from the medical records. This retrospective, non-controlled observational study was approved by the local ethics commission (01.53.01(2013/2006/KAP) 012).

\section{Surgical Procedure}

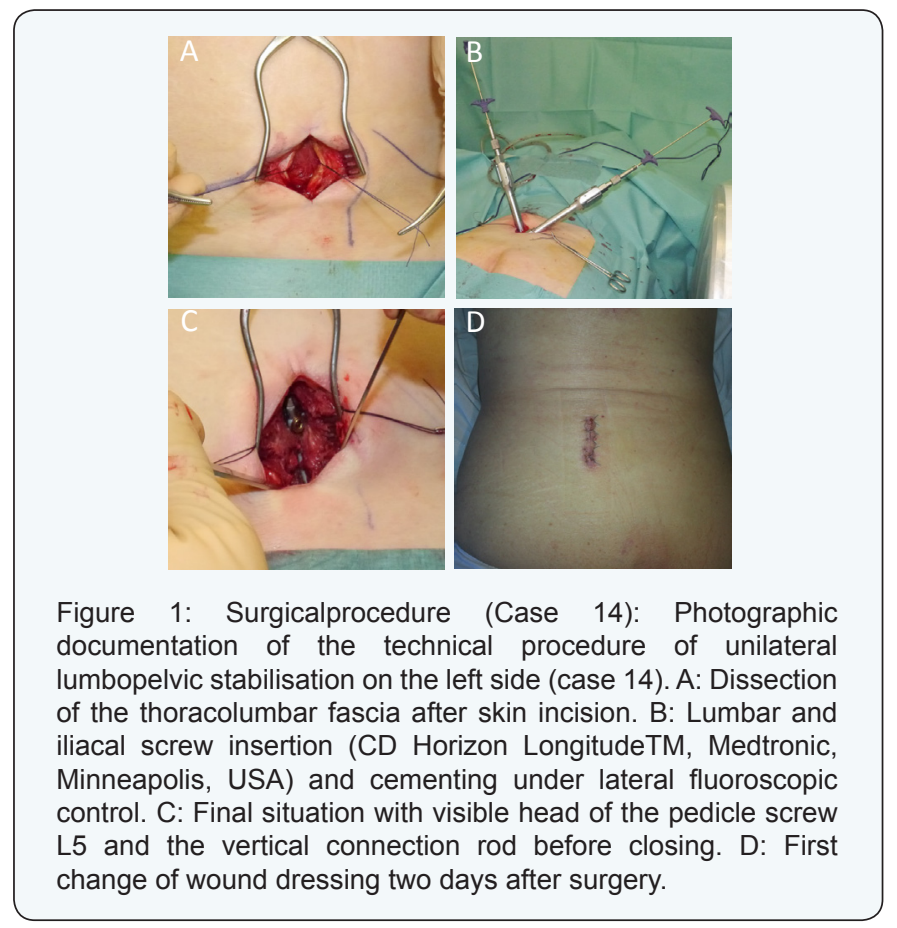

All surgeries were performed by the first, second or last author. Bilateral stabilisations were done by two surgeons. All procedures were performed in a prone position with standardised padding of all contact points, and the same polyaxial multi-level system (CD Horizon LongitudeTM, Medtronic, Minneapolis, USA) was used for dorsal instrumentation. In cases of unilateral mobilisation, the skin incision was done approximately $3 \mathrm{~cm}$ paramedian to the midline incision, starting from the fourth lumbar vertebral body and continuing parallel to the midline to the posterior iliac spine (Figure 1). Incision length did not exceed $5 \mathrm{~cm}$. In cases of bilateral lumbopelvic stabilisation, the skin incision was identical on both sides. The thoracolumbar fascia was exposed and split longitudinally, medial to the sacrospinal muscle. To expose the transverse process, the sacrospinal mass was held laterally by a self-retractor. To insert the distal iliac screw, the sacrospinal muscle was partially blunt dissected to expose the anterior and posterior border of the posterior iliac spine. For bilateral lumbopelvic stabilisation, the approaches were carried out successively and tamponade was used to reduce blood loss while performing the other side.

In cases of degenerative scoliosis, previously consolidated vertebral body fracture of L5 or moderate-to-severe anterolisthesis, it is often more difficult to enter the fifth lumbar pedicel. In such cases, we lengthen the lumbopelvic stabilisation up to the forth vertebral body. Under fluoroscopic guidance, the fourth or fifth lumbar pedicle was identified and then opened with a Jamshidi $®$ needle. The pedicel screw was then inserted through the previously placed guide wire. The entry point for the iliac screw was located posteriorly and medially of the posterior iliac spine. The needle was inserted only a few millimetres into the bone towards the supra acetabular region. The screw guide wire was then carefully inserted under fluoroscopic control to secure the direction and under digital control to prevent cortical perforation. If the entry point and the wire direction are correct, this technique should ensure the strongest screw anchorage according the pylon concept [16]. The iliac screw $(7.5 \times 55 \mathrm{~mm})$ was then inserted, giving particular attention to the depth. If the screw is not inserted properly or the entry point is placed too anteriorly, the screw head may irritate the thoracolumbar fascia and cause chronic pain. Once the pedicle and iliac screw were correctly placed, the vertical connection rod was inserted medial to the sacrospinal muscle. The fascia was closed with care to avoid irritation by the iliac screw head, the subcutaneous tissue was also adjusted and the skin opening was closed. All patients had immediate full weight bearing mobilisation within the first 24 hours after surgery. First radiographic imaging of the lumbar spine and pelvis were done after weight bearing. For patients with cement augmented screws, an additional thoracic radiograph was done to exclude a cement embolus.

\section{Outcomes}

Data gathered from medical records included posttraumatic status and findings from radiographs. Assessment tools such as VAS (Visual Analogue Scale, from 0 to $10,0=$ no pain, $10=$ very strong pain), the Barthel Index and Instrumental Activity of Daily Living (IADL) were used to document indicators postoperatively at 6 weeks, 3 months and 6 months (Figure 2). Conventional radiographs were done postoperatively at 6 weeks, 
3 months and 6 months. To confirm complete fracture healing, an additional CT scan of the pelvis was done after 6 months (Figure 2). Additionally, factors such as the delay to surgery, time of operation, duration of the hospital stay, complications and the need for orthopaedic hardware removal were extracted from the records.

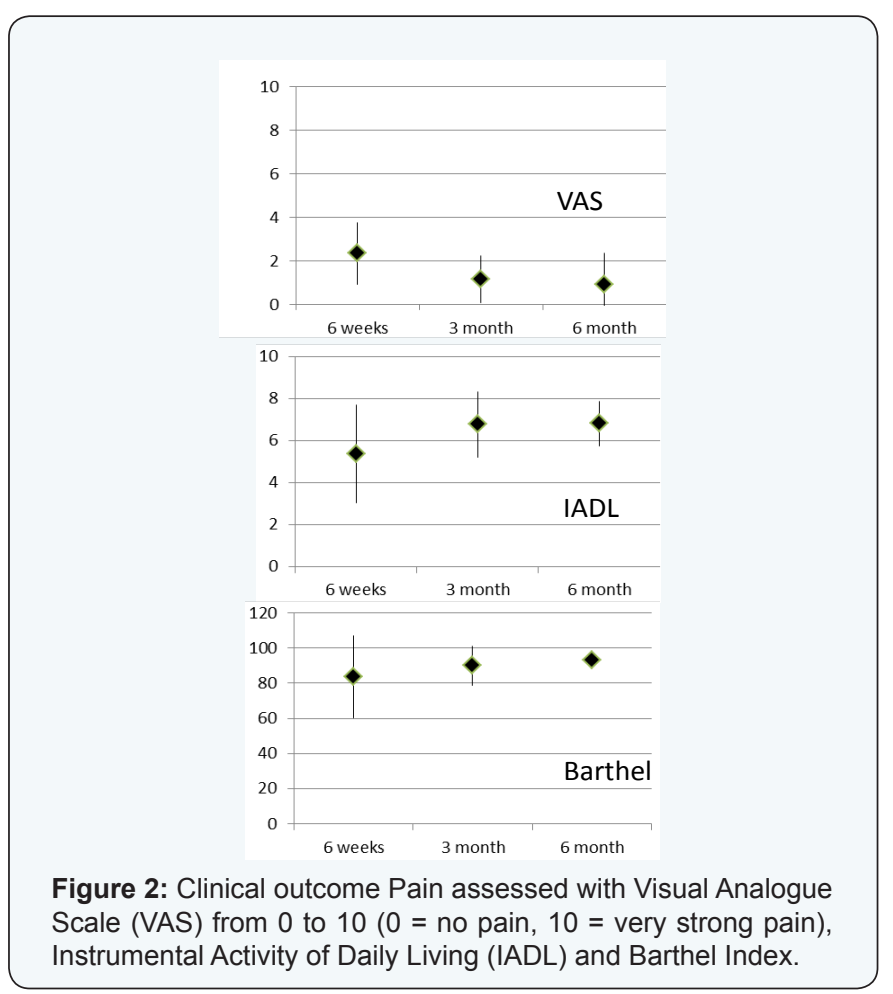

\section{Statistical Analysis}

Descriptive statistics were used to analyse clinical scores. A two-tailed paired Student's t-test was used for normally distributed data. The significance level was set at $\mathrm{p}<0.05$.All tests were conducted in IBM $\AA$ SPSS $\AA$ Statistics for Windows Version 21.0 (Armonk, NY).

\section{Results}

This series includes 14 patients with a mean age of 72.8 years, $\mathrm{SD} \pm 11.6$, range 53-91) who underwent either unilateral (6) or bilateral (8) lumbopelvic stabilisation during a 12 month period. Ten patients were female.The pelvic fracture patterns, as well as patient characteristics and operative procedure, are outlined in Table 1.Six patients had the following concomitant injuries: case 3 had three pathological thoracic vertebral fractures (Th3, Th4, Th6) type A1 (according the Magerl classification) [17], two patients (case 4 and 7) had concomitant left-sided fracture of the transverse process of L5; one kyphoplasty of vertebral body Th12 was done in case 8 (Magerl A1); case 10 had a concomitant proximal humeral fracture (AO 11-A3) on the right side and a vertebral body fracture of Th12 (Magerl A3) that were stabilised with minimally invasive transdeltoidal plating and a spondylodesis Th11 to L1, respectively; and one distal radius fracture (AO 23-A2) was stabilised with open reduction and internal plate fixation (case 12).

\section{Patient satisfaction}

Scores from clinical assessments are provided in (Figure 2). There was a statistically significant improvement in the scores of IADL and Barthel Index between the 6 week follow up and the final assessment after 6 months (IADL $p=0.03$, Barthel Index $p=0.01$ ). Three patients complained of pre-traumatic iliosacral and lumbosacral pain due to previous iliosacral arthritis and lumbosacral anterolisthesis. At the final 6 month follow up assessment, 7 patients had no residual pain (mean VAS0.9, SD \pm 1.3 , range 0 to 4 ). 12 patients were satisfied and very satisfied with the result and would do the operation again.

\section{Radiographs and medical outcomes}

Final CT scans at 6 month follow up visits were done for 12 patients ( 2 patients died before final assessment). Complete fusion of the posterior pelvic ring was confirmed in all 12 cases (Figure 3). Eleven patients also had a ventral pelvic ring fracture, but only 4 of the fractures had to be surgically stabilised. One patient (case 12) showed a delayed union of the inferior pubic ramus and reported at the final assessment minor residual pain while in a seated position (VAS 1). In 10 patients, the ventral pelvis ring was completely fused after 6 month.

Patients with ventral pelvic fracture are identified in Table 1. In case 4 , the ventral approach led to a thrombotic occlusion of the left external iliac artery two days after surgery and an iliacofemoral bypass was necessary for complete reperfusion of the left leg. A transient partial foot extensor paresis on the left side was noted preoperatively in one female patient (case 13). The right-sided transforaminal sacrum fracture was stabilised by lumbopelvic instrumentation while the contralateral iliosacral diastasis was compressed by a single iliosacral screw. Complete neurological capacity was restored after six months. Two elderly patients (case 7 and 11) suffered from pre- and postoperative recurrent falls and were readmitted to the hospital due to a pertrochanteric femur fracture (case 7, 58 days after lumbopelvic stabilisation) or a subtrochanteric fracture (case 11, 124 days after lumbopelvic stabilisation). Both fractures were stabilised using intramedullary nailing. Two patients died and did not reach the final follow up. The first patient (case 2) died 8 weeks after surgery due to cardiac and pulmonary decompensation. The second patient (case 3) with multiple myeloma died 20 days after surgery due to tumour-associated renal failure. 
Table 1: Description of patient characteristics, surgical procedure and hospitalisation; Fracture type: classified according to the Denis Classification; Cement: use of cement augmented ornon-cementedscrews; DS: Delay of surgery; OT: Operation time represents only the time for the Lumbopelvic stabilisation, either unilateral or bilateral; HS: Hospital stay.

\begin{tabular}{|c|c|c|c|c|c|c|c|c|c|}
\hline Case & Age & Gender & Fracture type & $\begin{array}{c}\text { Procedure } \\
\text { posterior ring }\end{array}$ & $\begin{array}{l}\text { Procedure } \\
\text { ventral } \\
\text { ring }\end{array}$ & $\begin{array}{l}\text { Type of } \\
\text { screw }\end{array}$ & DS (days) & $\begin{array}{c}\text { OT } \\
\text { (minutes) }\end{array}$ & $\begin{array}{c}\text { HS } \\
\text { (days) }\end{array}$ \\
\hline 1 & 87 & $\mathrm{f}$ & $\begin{array}{l}\text { Zone } 3 \text { ( } \mathrm{H} \text { fracture), intact } \\
\text { ventral pelvic ring }\end{array}$ & $\begin{array}{l}\text { L5 to os ileum } \\
\text { bilateral }\end{array}$ & none & cemented & 21 & 70 & 13 \\
\hline 2 & 84 & $\mathrm{f}$ & $\begin{array}{c}\text { Zone } 2 \text { bilateral, fractured } \\
\text { ventral pelvic ring left } \\
\text { side }\end{array}$ & $\begin{array}{l}\text { L5 to os ileum } \\
\text { bilateral }\end{array}$ & none & cemented & 18 & 88 & 11 \\
\hline 3 & 82 & $\mathrm{f}$ & $\begin{array}{l}\text { Zone } 2 \text { left side, intact } \\
\text { ventral pelvic ring }\end{array}$ & $\begin{array}{l}\text { L4 to os ileum } \\
\text { bilateral }\end{array}$ & none & cemented & $\begin{array}{l}\text { Unknown } \\
\text { due to } \\
\text { pathological } \\
\text { condition }\end{array}$ & 70 & 20 \\
\hline 4 & 68 & $\mathrm{f}$ & $\begin{array}{l}\text { Zone } 1 \text { bilateral, fractured } \\
\text { ventral pelvic ring left } \\
\text { side }\end{array}$ & $\begin{array}{l}\text { L4 to os ileum } \\
\text { bilateral }\end{array}$ & $\begin{array}{l}\text { Minimal } \\
\text { invasive } \\
\text { plating left } \\
\text { side }\end{array}$ & uncemented & 173 & 55 & 15 \\
\hline 5 & 73 & $\mathrm{f}$ & $\begin{array}{l}\text { Zone } 2 \text { right side, } \\
\text { fractured ventral pelvic } \\
\text { ring right side }\end{array}$ & $\begin{array}{l}\text { L5 to os ileum right } \\
\text { side }\end{array}$ & $\begin{array}{c}\text { Secondary } \\
\text { minimal } \\
\text { invasive } \\
\text { plating right } \\
\text { side }\end{array}$ & cemented & 12 & 54 & 16 \\
\hline 6 & 75 & $\mathrm{~m}$ & $\begin{array}{l}\text { Zone } 1 \text { left side, fractured } \\
\text { ventral pelvic ring left } \\
\text { side }\end{array}$ & $\begin{array}{l}\text { L5 to os ileus left } \\
\text { side }\end{array}$ & none & cemented & $\begin{array}{l}\text { Unknown } \\
\text { due to } \\
\text { recurrent } \\
\text { falls }\end{array}$ & 60 & 12 \\
\hline 7 & 91 & $\mathrm{f}$ & $\begin{array}{l}\text { Zone } 1 \text { bilateral, fractured } \\
\text { pelvic ring left side }\end{array}$ & $\begin{array}{l}\text { L5 to os ileum } \\
\text { bilateral }\end{array}$ & none & cemented & 3 & 80 & 10 \\
\hline 8 & 73 & $\mathrm{f}$ & $\begin{array}{l}\text { Zone } 3 \text { ( } \mathrm{H} \text { fracture), intact } \\
\text { ventral pelvic ring }\end{array}$ & $\begin{array}{l}\text { L4 to os ileum } \\
\text { bilateral }\end{array}$ & none & cemented & 14 & 90 & 14 \\
\hline 9 & 70 & $\mathrm{~m}$ & $\begin{array}{l}\text { Zone } 1 \text { right side, } \\
\text { fractured ventral pelvic } \\
\text { ring right side }\end{array}$ & $\begin{array}{l}\text { L5 to os ileum right } \\
\text { side }\end{array}$ & none & uncemented & 4 & 40 & 10 \\
\hline 10 & 63 & $\mathrm{~m}$ & $\begin{array}{c}\text { Zone } 3 \text { ( } \mathrm{H} \text { fracture), pubic } \\
\text { diastasis (open book) }\end{array}$ & $\begin{array}{l}\text { L5 to os ileum } \\
\text { bilateral }\end{array}$ & $\begin{array}{l}\text { Secondary } \\
\text { plating } \\
\text { of the } \\
\text { symphysis }\end{array}$ & uncemented & 2 & 40 & 20 \\
\hline 11 & 61 & $\mathrm{f}$ & $\begin{array}{c}\text { Zone } 2 \text { left side, fractured } \\
\text { ventral pelvic ring left } \\
\text { side }\end{array}$ & $\begin{array}{l}\text { L5 to os ileum } \\
\text { bilateral }\end{array}$ & none & cemented & 7 & 65 & 14 \\
\hline 12 & 57 & $\mathrm{f}$ & $\begin{array}{l}\text { Zone } 2 \text { right side, } \\
\text { fractured ventral pelvic } \\
\text { ring right side }\end{array}$ & $\begin{array}{l}\text { L5 to os ileum and } \\
\text { iliosacral screw right } \\
\text { side }\end{array}$ & none & uncemented & 3 & 55 & 14 \\
\hline 13 & 53 & $\mathrm{~m}$ & $\begin{array}{l}\text { Zone } 1 \text { right side, anterior } \\
\text { iliosacral joint rupture } \\
\text { left side with open book } \\
\text { fracture }\end{array}$ & $\begin{array}{l}\text { L5 to os ileum right } \\
\text { side, ilosacral screw } \\
\text { left side }\end{array}$ & $\begin{array}{l}\text { Symphysis } \\
\text { plating }\end{array}$ & uncemented & 2 & 115 & 12 \\
\hline 14 & 83 & $\mathrm{f}$ & $\begin{array}{l}\text { Zone } 1 \text { left side, fractured } \\
\text { ventral pelvic ring left } \\
\text { side }\end{array}$ & $\begin{array}{l}\text { L5 to os ileum left } \\
\text { side }\end{array}$ & none & cemented & 6 & 43 & 14 \\
\hline
\end{tabular}



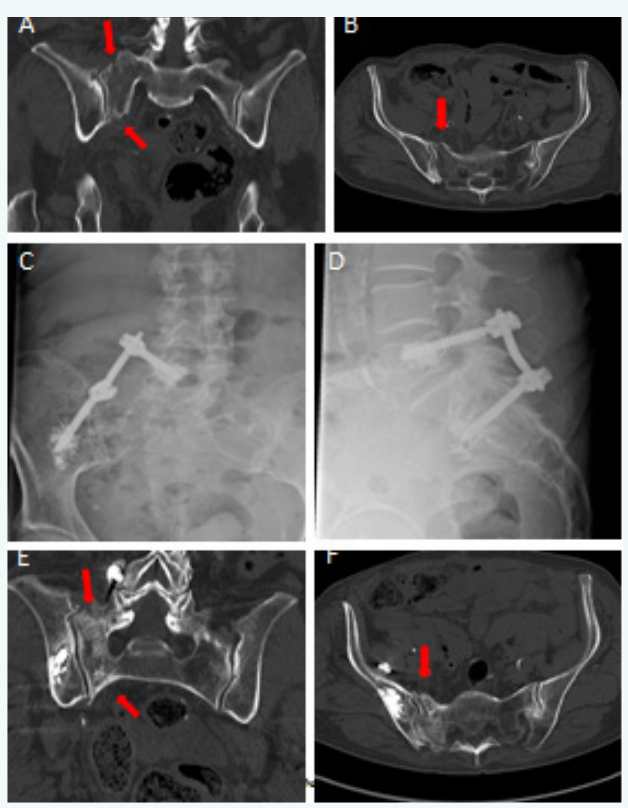

Figure 3: Radiographic example (Case 5): Preoperative CT scan (A: coronal plane, B: transverse plane) with visible fracture of the sacral mass (arrows). C and D: ap (C) and lateral (D) conventional view two days postoperatively. $\mathrm{E}$ and $\mathrm{F}$ : The CT scan 6 month after surgery shows a complete fusion of the sacral mass fracture in the coronal $(E)$ and transverse $(F)$ plane (arrows).

\section{Complications}

A secondary dislocation of the ventral pelvic ring occurred in one patient (case 5) 60 days after primary posterior stabilisation. The dislocation was stabilised by minimally invasive plating. Case 10 had an open book fracture and was operated at two stages during the same hospital stay. There was no wound healing disorders or deep wound infection in any patients.

\section{Operation time and hospitalisation}

The mean operation time was 79.5 minutes $(\mathrm{SD} \pm 37.9$, range 40 to 190), which includes all interventions done during the same surgical session. However, the mean length of lumbopelvic stabilisation for either unilateral or bilateral cases was 66.0 minutes ( $S D \pm 21.5$, range 40 to 115 ). Patients who underwent a unilateral lumbopelvic stabilisation had an average operation time of 49 minutes (SD \pm 8.3 , range 40 to 60 ) while the mean duration of bilateral lumbopelvic stabilisation was 72 minutes ( $\mathrm{SD} \pm 16.9$, range 40 to 90 ). The average hospital stay was 13.9 days (SD \pm 3.1 , range 10 to 20 ).

\section{Discussion}

During the time period of our investigation, we identified 22 patients over 50 years of age who were treated for pelvic fractures, 8 of them conservatively. All patients who underwent stabilisation $(n=14)$ could be mobilised immediately after operation. 12 patients were completely satisfied or very satisfied with the result, and all reported they would do the operation again. The operation time was short for both unilateral and bilateral procedures.

The lumbopelvic stabilisation without iliosacral screw (2-point fixation) allows good screw placement and sufficiently neutralizes the vertical shear forces. In our patients, we most often used a L5 screw ( $\mathrm{n}=11)$, only in 3 patients the lumbar screw was placed on L4 due to degeneration and unsafe radiological presentation of the pedicle L5. S1 placement would give a higher stability but it is associated with a higher rate of nerve damage. The triangular osteosynthesis is a combination of the lumbopelvic stabilisation and the iliosacral screw which neutralizes vertical and horizontal forces [18,19]. Such a 3-point fixation was performed to maintain a sufficient fracture reduction in one patient with a slight-to-moderate fracture dislocation (case 12). The placement of a single iliosacral gives adequate stability mostly in younger patients and/or those with good bone quality (case 13). All fractures of the ventral pelvic ring healed within 6 months, and secondary dislocation was observed in only one patient (case 5). It seems that in cases of a single fracture of the sacrum and/ or concomitant non-displaced ventral pelvic ring fractures, a single lumbopelvic osteosynthesis provides sufficient stability for proper fracture healing. However, in a few cases, it might lead to a secondary dislocation which would require further stabilisation. Patients with an open book fracture must be stabilised with a ventral symphyseal plate and we strongly recommend the use of plating in cases of dislocated ventral pelvic ring.

We prefer the posterolateral approach for unilateral and bilateral lumbopelvic stabilisation described by Watkins [20] which results in less soft tissue damage and wound healing disorders than the classic midline incision [21]. In our cohort of 14 patients, we attribute the lack of wound healing problems to the less invasive approach used. The LongitudeTM System allows a dorsal instrumentation through two small incisions. Since the 2-incision technique is comparable or slightly more invasive, we performed stabilisation through a small single approach. Furthermore, the vertical connection rod may be placed under visual view to ensure that it does not irritate the thoracolumbar fascia.

Two patients included in our investigation died before final assessments were possible 20 days for case 3 and 8 weeks for case 2 . The first patient was examined 6 weeks postoperatively and reported significant reduction in pain after the operation, but mobilisation was limited to a walking frame. Two weeks after this assessment, the patient died due to cardio-pulmonary decompensation. The second patient suffered from multiple myeloma and had severe pain due to a pathological sacrum fracture on the left side. In addition, the skeletal radiographs showed multiple dissemination of the tumour. The decision to perform surgery was based on the patient's inability to mobilise and to reduce the reliance on pain medication. Postoperatively, the patient's increasing creatinine values eventually resulted 
in anuric renal failure 20 days after surgery, most likely tumour-induced. In light of these circumstances, we believe this procedure is not advisable in cases of disseminated endstage multiple myeloma, but a good option in stable patients for palliative reasons. Although these deaths were considered unrelated to the procedure, published one-year-mortality rates after pelvic ring fractures range from $8 \%$ to $27 \%$ [22-25]. The primary limitation of the study was the small sample size due to the low incidence of these cases with this indication. In addition, we do not routinely perform pre- or postoperative osteo-densitometry to verify bone quality. The decision to use a cement augmented screw is based on intra operative findings regarding the bone density and the age.

\section{Conclusion}

In conclusion, we found the less invasive lumbopelvic stabilisation an effective technique for traumatic unilateral and bilateral posterior pelvic ring fractures in patients over 50 . Sufficient stability can be achieved, even in patients with poor bone quality, and all patients may be mobilised with full weight bearing shortly after surgical intervention.

\section{Acknowledgment}

We thank to Ms. Welter for controlling the statistical analysis and grammatical correction of the manuscript.

\section{Conflict of Interest}

There is no economic or any conflict of interest of any authors of this manuscript

\section{References}

1. Organization WH (2015) Global Health and Aging. In: National Institut on Aging, US National Institute of Health 2011, USA.

2. Boufous S, Finch C, Lord S, Close J (2005) The increasing burden of pelvic fractures in older people, New South Wales, Australia. Injury 36(11): 1323-1329.

3. Islam S, Liu Q Chines A, Helzner E (2009) Trend in incidence of osteoporosis-related fractures among 40- to 69-year-old women: analysis of a large insurance claims database, 2000-2005. Menopause 16(1): 77-83.

4. Kannus P, Palvanen M, Niemi S, Parkkari J, Järvinen M (2000) Epidemiology of osteoporotic pelvic fractures in elderly people in Finland: sharp increase in 1970-1997 and alarming projections for the new millennium. Osteoporos Int 11(5): 443-448.

5. King AB, Tosteson AN, Wong JB, Solomon DH, Burge RT, et al. (2009) Interstate variation in the burden of fragility fractures. J Bone Miner Res 24(4): 681-692.

6. Andrich S, Haastert B, Neuhaus E, Neidert K, Arend W, et al. (2015) Epidemiology of Pelvic Fractures in Germany: Considerably High Incidence Rates among Older People. PLoS One 10(9) :e0139078.

7. Griffin Damian R, Starr Adam J, Reinert Charles M, Jones Alan L, Whitlock Shelly (2003) Vertically unstable pelvic fractures fixed with percutaneous iliosacral screws: does posterior injury pattern predict fixation failure? Journal of Orthopaedic Trauma 17(6): 399-405.
8. Routt ML Jr, Kregor PJ, Simonian PT, Mayo KA (1995) Early results of percutaneous iliosacral screws placed with the patient in the supine position. J Orthop Trauma 9(3): 207-214.

9. Routt ML Jr, Simonian PT, Mills WJ (1997) Iliosacral screw fixation: early complications of the percutaneous technique. J Orthop Trauma 11(8): 584-589.

10. Breuil V, Roux CH, Testa J, Albert C, Chassang M, et al. (2008) Outcome of osteoporotic pelvic fractures: an underestimated severity. Survey of 60 cases. Joint Bone Spine 75(5): 585-588.

11. Zhang HY, Thongtrangan I, Balabhadra RS, Murovic JA, Kim DH (2003) Surgical techniques for total sacrectomy and spinopelvic reconstruction. Neurosurg Focus 15(2): E5.

12. Moshirfar A, Rand FF, Sponseller PD, Parazin SJ, Khanna AJ, et al. (2005) Pelvic fixation in spine surgery. Historical overview, indications, biomechanical relevance, and current techniques. J Bone Joint Surg Am 87(2): 89-106.

13. Vaccaro AR, Kim DH, Brodke DS, Harris M, Chapman JR, et al. (2004) Diagnosis and management of sacral spine fractures. Instr Course Lect 53: 375-385.

14. Keel MJ, Benneker LM, Siebenrock KA, Bastian JD (2011) Less invasive lumbopelvic stabilization of posterior pelvic ring instability: technique and preliminary results. J Trauma 71(3): E62-70.

15. Schildhauer TA, Bellabarba C, Nork SE, Barei DP, Routt ML (2006) Decompression and lumbopelvic fixation for sacral fracturedislocations with spino-pelvic dissociation. J Orthop Trauma 20(7): 447-457.

16. Schwend RM, Sluyters R, Najdzionek J (2003) The pylon concept of pelvic anchorage for spinal instrumentation in the human cadaver. Spine (Phila Pa 1976) 28(6): 542-547.

17. Magerl F, Aebi M, Gertzbein SD, Harms J, Nazarian S (1994) A comprehensive classification of thoracic and lumbar injuries. Eur Spine J 3(4): 184-201.

18. Schildhauer TA, Josten Ch, Muhr G (2006) Triangular osteosynthesis of vertically unstable sacrum fractures: a new concept allowing early weight-bearing. J Orthop Trauma 20(1): S44-51.

19. Schildhauer TA, Ledoux WR, Chapman JR, Henley MB, Tencer AF, et al. (2003) Triangular osteosynthesis and iliosacral screw fixation for unstable sacral fractures: a cadaveric and biomechanical evaluation under cyclic loads. J Orthop Trauma 17(1): 22-31.

20. WATKINS MB (1953) Posterolateral fusion of the lumbar and lumbosacral spine. J Bone Joint Surg Am 35-A(4): 1014-1018.

21. Roetman B, Schildhauer TA (2013) [Lumbopelvic stabilization for bilateral lumbosacral instabilities: indications and techniques]. Unfallchirurg116(11): 991-999.

22. Balogh Z, King KL, Mackay P, McDougall D, Mackenzie S, et al. (2007) The epidemiology of pelvic ring fractures: a population-based study. J Trauma 63(5): 1066-1073.

23. J TraumaKrappinger D, Kammerlander C, Hak DJ, Blauth M (2010) Low-energy osteoporotic pelvic fractures. Arch Orthop Trauma Surg 130(9): 1167-1175.

24. Morris RO, Sonibare A, Green DJ, Masud T (2000) Closed pelvic fractures: characteristics and outcomes in older patients admitted to medical and geriatric wards. Postgrad Med J 76(900): 646-650.

25. Prieto-Alhambra D, Avilés FF, Judge A, Van Staa T, Nogués X, et al. (2012) Burden of pelvis fracture: a population-based study of incidence, hospitalisation and mortality. Osteoporos Int 23(12): 2797-2803. 